\title{
Lateral and Overturning Resistance of Wind Turbine Foundations Reinforced with Piles on Bedrock by Modelling Experiments
}

\author{
Gichun Kang ${ }^{1}{ }^{\mathbb{D}}$, Seong-Kyu Yun ${ }^{2} \mathbb{( D}$, Tae-Hyung Kim ${ }^{3}$ and Jiseong Kim ${ }^{4, *}$ \\ 1 Department of Civil Engineering, College of Engineering, Gyeongsang National University, \\ Jinju 52828, Korea; gkang@gnu.ac.kr \\ 2 Engineering Research Institute, Gyeongsang National University, Jinju 52828, Korea; tjdrb330@gnu.ac.kr \\ 3 Department of Civil Engineering, Korea Maritime and Ocean University, Pusan 49112, Korea; \\ kth67399@kmou.ac.kr \\ 4 Department of Cadastre \& Civil Engineering, Vision College of Jeonju, Jeonju 55069, Korea \\ * Correspondence: kimjی@jvision.ac.kr; Tel.: +82-63-220-3885
}

check for

updates

Citation: Kang, G.; Yun, S.-K.; Kim, T.-H.; Kim, J. Lateral and Overturning Resistance of Wind Turbine

Foundations Reinforced with Piles on Bedrock by Modelling Experiments. J. Mar. Sci. Eng. 2021, 9, 919. https:// doi.org/10.3390/jmse9090919

Academic Editors:

Pasqualino Corigliano and

Vincenzo Piscopo

Received: 13 August 2021

Accepted: 22 August 2021

Published: 24 August 2021

Publisher's Note: MDPI stays neutral with regard to jurisdictional claims in published maps and institutional affiliations.

Copyright: (c) 2021 by the authors. Licensee MDPI, Basel, Switzerland. This article is an open access article distributed under the terms and conditions of the Creative Commons Attribution (CC BY) license (https:/ / creativecommons.org/licenses/by/ $4.0 /)$.

\begin{abstract}
This study evaluated the lateral and overturning resistance of wind turbine foundations reinforced with piles on bedrock through model experiments. In particular, changes in lateral and overturning resistance of wind turbine foundations were analyzed according to cross-sectional size and the presence of piles of wind turbine foundations. As a result, by reducing the cross-section, the lateral resistance of the pile-reinforced wind turbine foundation was compared to the existing wind turbine foundation with large cross-sections and was shown to be 1.68 times greater. In the case of vertical displacements affecting overturning, the safety of overturning was also greater, as the vertical displacement of the pile-reinforced wind turbine foundation was $36 \%$ smaller than the existing wind turbine foundation. As a result of the unidirectional cyclic load on a pile-reinforced wind turbine foundation, lateral resistance value was similar to that of the static load in target displacement value, and it showed that the elastic resilience was very large due to pile reinforcement. According to the bending moment measurement of piles embedded in wind turbine foundations and bedrock, bending moments were large in the order of the front row, the right-hand row, and the back row, while the maximum bending moment generation was found on the boundary surface of the wind turbine foundation and the rubble mound layer for the front row, as well as on the boundary surface of the rubble mound layer and bedrock for the right-hand row and back row.
\end{abstract}

Keywords: wind turbine foundation; pile; lateral resistance; overturning

\section{Introduction}

Interest in wind turbines has increased as demand for renewable energy has increased recently. Wind turbines tend to be built in the sea rather than inland due to enlargement. Various foundation forms are applied to support wind turbine towers as they are built in the sea. Typical foundation types include gravity-based foundation, monopile foundation, floating foundation, and suction bucket foundation. For the enlargement of offshore wind turbines, it is important to determine the economic foundation form due to the increase in the foundation construction costs of offshore wind turbine structures. In addition, in the case of offshore wind turbine structures, the lateral resistance and overturning of structures are important due to wind and wave forces. Therefore, there is a need for the activities of offshore wind turbine structures that can be generated due to lateral loads, especially for measures that ensure stability in relation to overturning. In order to increase the economic feasibility and stability of lateral resistance due to enlargement of offshore wind turbine structures, this study examined a new method of reducing the cross-section of wind turbine foundations to reinforce the gap between foundation and bedrock with piles. 
This method is similar to the Ticell method (Kim et al., 2020) [1], which has recently been reinforced with piles. The Ticell method is a method that maximizes resistance to activity by inserting piles into existing block-type methods. In other words, it implements bonding between blocks and tensile forces between the blocks and the ground through piles. The existing block-type method has a form in which the weight of the block itself and frictional force between the blocks resist the lateral load, and no bond exists between the block and the ground (Tsinker, 1997) [2]. Currently, in the case of the Tiecell method, there are research (Kang et al., 2021) [3] and construction cases applied to breakwaters and piers, but there have been no cases of application to offshore wind turbine foundation structures so far.

Since securing support is important for the foundation of offshore wind turbines, foundation form is different depending on ground conditions. Gravity-based foundations are applicable for well-grounded bedrock or dense sand ground but, if not, foundation methods such as monopile or suction bucket are applied (Negro et al., 2014; Esteban et al., 2015) [4,5]. For example, for suction bucket offshore wind turbine foundations, Houlsby et al. (2005) [6] and Kelly et al. (2006) [7] conducted field experiments to predict bucket-based dynamic responses to lateral and vertical loads in clay and sandy soil. As such, several studies have been undertaken on wind foundations in clay and in sandy ground. On the other hand, there has been a lot of research on relatively good ground in gravity-based offshore wind turbine foundations, where the loads of offshore wind turbine structures are transferred directly to the ground through the foundation (Esteban et al., 2019; Li et al., 2018) [8,9]. This study is a new type of foundation that is different from existing offshore wind power foundations, and it will be meaningful for analyzing the resistance and behavior characteristics in rocky foundations.

In this study, the applicability of offshore wind turbine foundation structures reinforced with piles on bedrock was examined through model experiments. It is judged that the results of this study can help establish basic data and theories for designing economical and safe offshore wind turbine foundation structures.

\section{Modeling Experiment}

In this study, the gravity foundation installed on the bedrock was studied, and model experiments were conducted to study the lateral resistance of wind turbine foundations reinforced with piles on the bedrock. Figure 1 represents the sectional plan and block type model of a wind turbine tower foundation. As they were used for a comparison between the foundation reinforced with piles and the existing gravity foundation, the experiments were conducted by ignoring the blocks for the foundation. The experiments indicate that the foundation was made from a lump of cement mortar, as shown in Figure 2. The circular gravity foundation applied to the actual site has a diameter of $20 \mathrm{~m}$ and a thickness of $4 \mathrm{~m}$. To fit this into model experiments, law of Iai (1989) [10] was applied. It was in accordance with the parameters presented in Table 1, and considered as Type 2. As it was a prototype, the material's figures were applied as shown in Table 2.

\subsection{Model Tower Foundation and Bedrock}

Cement mortar was used to implement tower foundations and bedrock, and the model was produced through the production of a mold, as shown in Figure 2. The bedrock and size downed (diameter in prototype $=16 \mathrm{~m}$ ) were placed with the model piles joined together to simulate pile penetration during the experiment. The model pile was removed after curing for 7 days, and the bedrock and foundation were sufficiently cured for more than 28 days to conduct model experiments. 


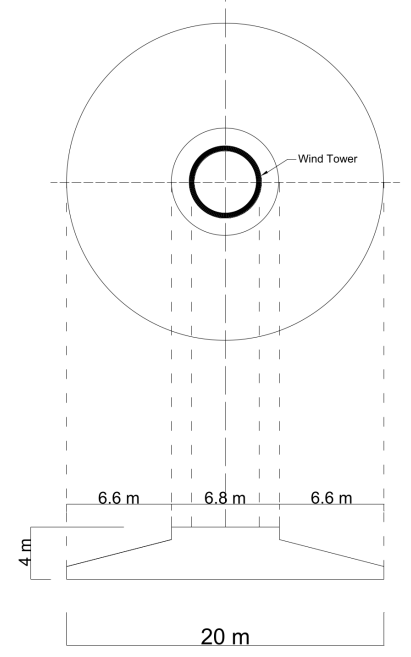

(a)

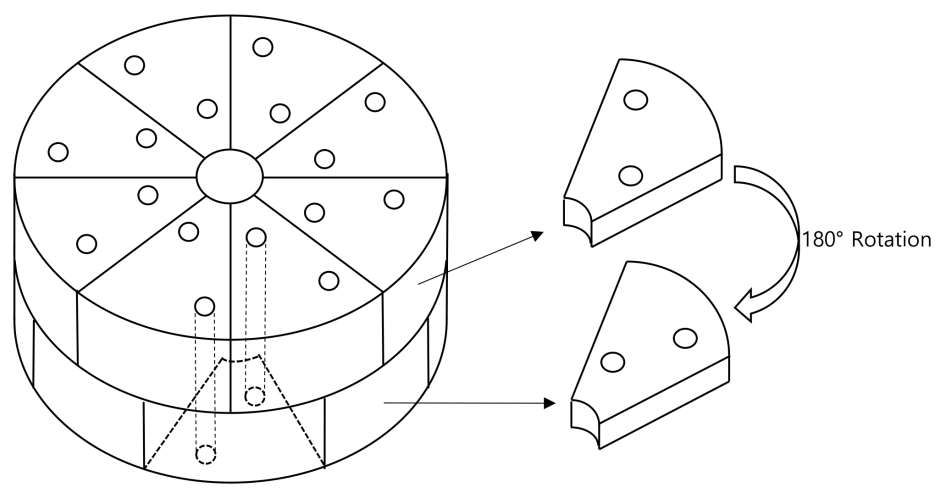

(b)

Figure 1. Sectional plan (a) and block type model (b) for foundation of wind tower.

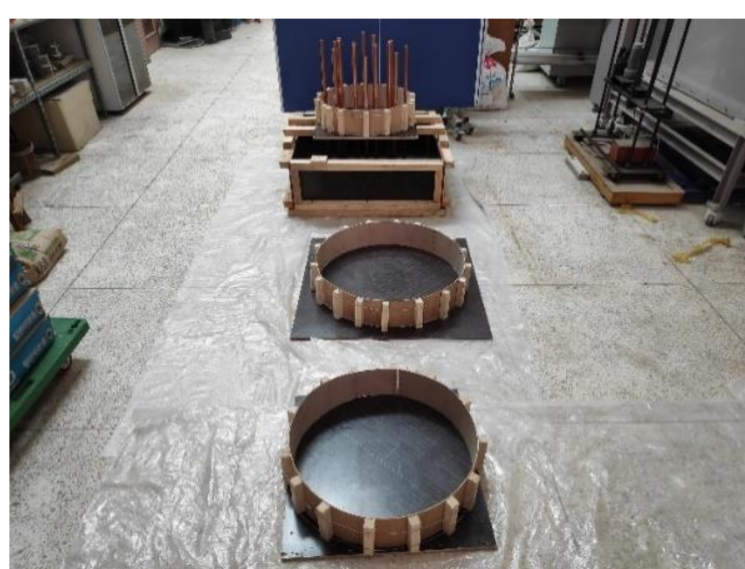

(a)

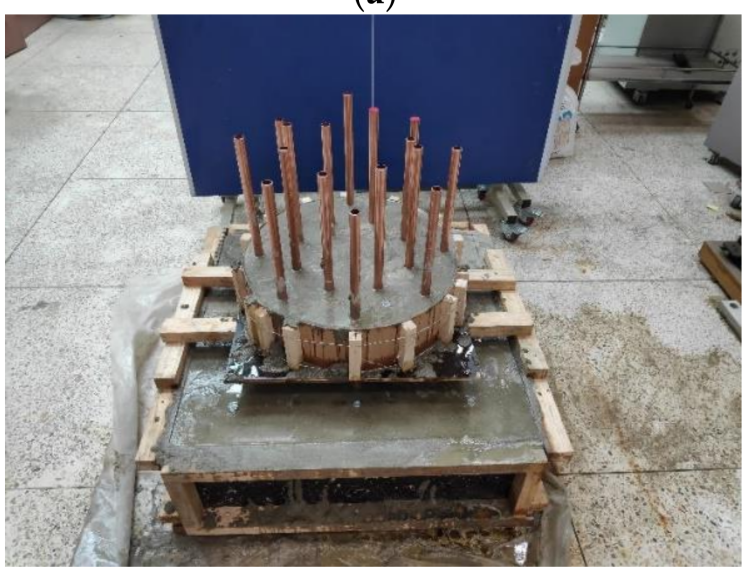

(c)

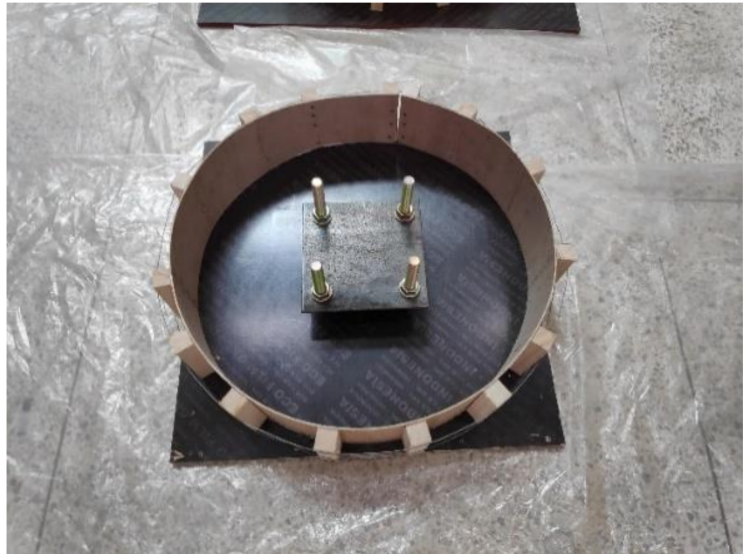

(b)

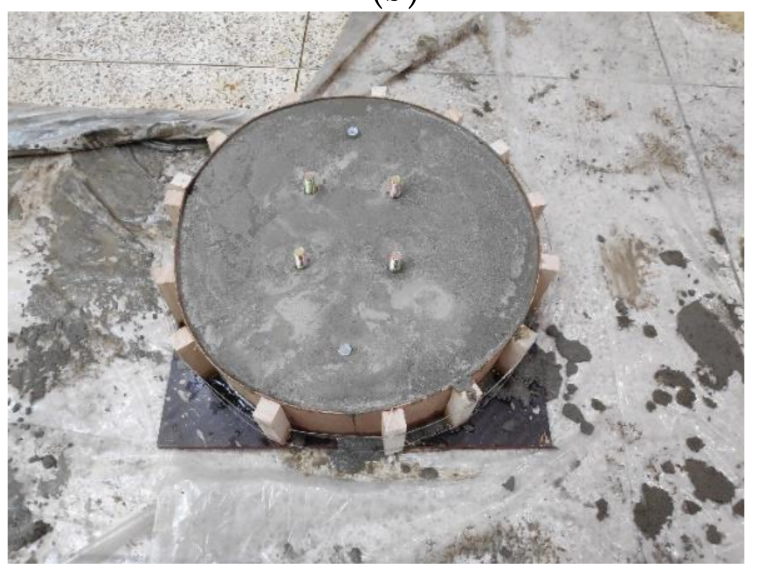

(d)

Figure 2. Wind turbine foundation and bedrock production: (a) cement mortar form; (b) buried the connection bolt for the wind turbine tower; (c) cement mortar placement for wind turbine foundation and bedrock; (d) existing wind-based mortar placement. 
Table 1. Generalized scaling law for model tests.

\begin{tabular}{cccc}
\hline Quantity & Scaling Factor & Model & Prototype \\
\hline Vertical length & $\lambda$ & 1 & 28.61 \\
Horizontal length & $\lambda$ & 1 & 28.61 \\
Density & 1 & 1 & 1 \\
Stress and pressure & $\lambda$ & 1 & 28.61 \\
Time & $\lambda^{3 / 4}$ & 1 & 12.37 \\
Acceleration & 1 & 1 & 1 \\
EI of pile/width & $\lambda^{7 / 2}$ & 1 & 125,260 \\
Displacement & $\lambda^{3 / 2}$ & 1 & 153.03 \\
Bending moment & $\lambda^{3}$ & 1 & $23,418.2$ \\
Strain & $\lambda^{1 / 2}$ & 1 & 5.35 \\
\hline
\end{tabular}

Table 2. Material properties for experiments.

\begin{tabular}{cccc}
\hline \multicolumn{2}{c}{ Type of Material } & Prototype (m) & Model (mm) \\
\hline \multirow{2}{*}{ Pile } & Diameter & 0.636 & 22.22 \\
& Length & 12 & 419.4 \\
\hline \multirow{2}{*}{ Wind tower } & Diameter & 4 & 139.8 \\
& Length & 97.16 & 3400.0 \\
\hline \multirow{2}{*}{ Loading point } & & 80.2 & 2800.0 \\
\multirow{2}{*}{$\begin{array}{c}\text { Foundation of wind } \\
\text { tower }\end{array}$} & Diameter & 20 & 699.1 \\
& Height & 16 & 559.3 \\
\hline \multirow{2}{*}{ In-situ } & Height & 4 & 139.8 \\
\hline \multicolumn{2}{c}{ Height of mound } & 8 & 279.6 \\
& Width & 24 & 838.9 \\
\hline
\end{tabular}

\subsection{Model Pile}

The piles used in the experiment were circular piles made of copper tubes, and the data are shown in Table 3. Five strain gauges were installed on the pile surface, as shown in Figure 3 , to measure the bending moment of the pile, and the connecting row was installed by drilling copper tube piles and guiding it internally to prevent disconnection.

Table 3. Properties of model pile.

\begin{tabular}{|c|c|c|c|c|c|}
\hline $\begin{array}{l}\text { Length } \\
\text { (mm) }\end{array}$ & $\begin{array}{l}\text { Diameter } \\
(\mathrm{mm})\end{array}$ & $\begin{array}{l}\text { Thickness } \\
\text { (mm) }\end{array}$ & $\begin{array}{c}\text { Young } \\
\text { Modulus, E } \\
\left(\mathrm{MN} / \mathrm{cm}^{2}\right)\end{array}$ & $\begin{array}{l}\text { Moment of } \\
\text { Inertia, I } \\
\left(\mathrm{cm}^{4}\right)\end{array}$ & $\begin{array}{c}\mathrm{EI} \\
\left(\mathrm{MN} \cdot \mathrm{cm}^{2}\right)\end{array}$ \\
\hline 420 & 22.22 & 1.65 & 12.25 & 0.567299 & 6.949413 \\
\hline
\end{tabular}

\subsection{Experiment Type}

The experiment involved 6 types of experiments, as shown in Table 4 . Case 1 simulates the wind foundation that is introduced to the actual site, with a diameter of $20 \mathrm{~m}$, which is the existing wind foundation. Case 2 is a reduction in the diameter of the wind foundation to $16 \mathrm{~m}$, and Case 3 is the insertion of piles into the reduced foundation. Case 4 and Case 5 show when the tower's weight is doubled and tripled, respectively. Moreover, Case 6 was performed to analyze the behavior caused by wind loads in the actual site as a case of cyclic loads. In Cases 3-6, the experiment was conducted by interpenetrating a total of 16 piles, with 8 inside and 8 outside, equally spaced, as shown in Figure 4. 


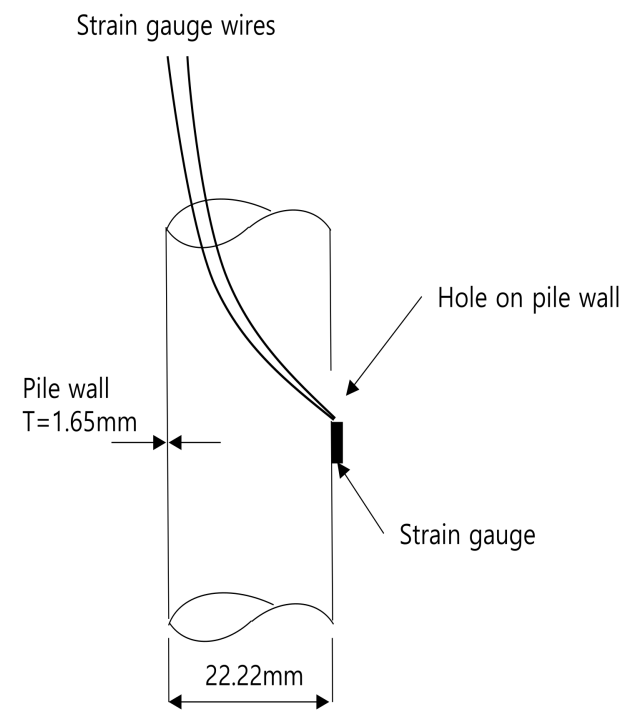

(a)

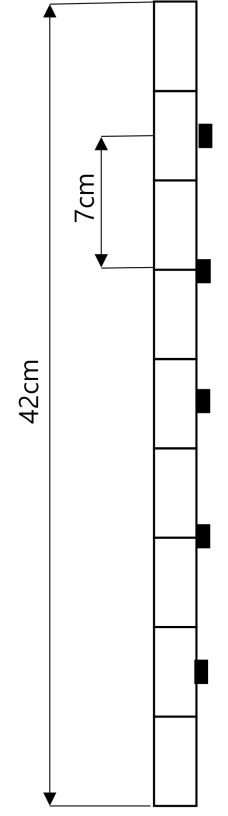

(b)

Figure 3. Strain gauge attachment method and location: (a) attachment method of strain gauge; (b) strain gauges mounted position.

Table 4. Experimental Case.

\begin{tabular}{|c|c|c|c|c|c|c|}
\hline & \multicolumn{2}{|c|}{ Diameter } & \multirow{2}{*}{$\begin{array}{c}\text { Pile } \\
\text { Penetration } \\
\text { Status }\end{array}$} & \multirow{2}{*}{$\begin{array}{l}\text { Loading } \\
\text { Condition }\end{array}$} & \multirow{2}{*}{$\begin{array}{l}\text { Weight of } \\
\text { Tower }\end{array}$} & \multirow{2}{*}{ Remarks } \\
\hline & Prototype & Model & & & & \\
\hline Case 1 & $20 \mathrm{~m}$ & $699.1 \mathrm{~mm}$ & $X$ & Static & 357.7 & \multirow{2}{*}{$\begin{array}{c}\text { Existing foundation } \\
\text { Size downed foundation }\end{array}$} \\
\hline Case 2 & $16 \mathrm{~m}$ & $559.3 \mathrm{~mm}$ & $X$ & Static & 357.7 & \\
\hline Case 3 & $16 \mathrm{~m}$ & $559.3 \mathrm{~mm}$ & 0 & Static & 357.7 & \multirow{4}{*}{$\begin{array}{l}\text { Size downed foundation } \\
\text { with piles }\end{array}$} \\
\hline Case 4 & $16 \mathrm{~m}$ & $559.3 \mathrm{~mm}$ & 0 & Static & 715.4 & \\
\hline Case 5 & $16 \mathrm{~m}$ & $559.3 \mathrm{~mm}$ & 0 & Static & 1073.1 & \\
\hline Case 6 & $16 \mathrm{~m}$ & $559.3 \mathrm{~mm}$ & 0 & Cyclic Loading & 357.7 & \\
\hline
\end{tabular}

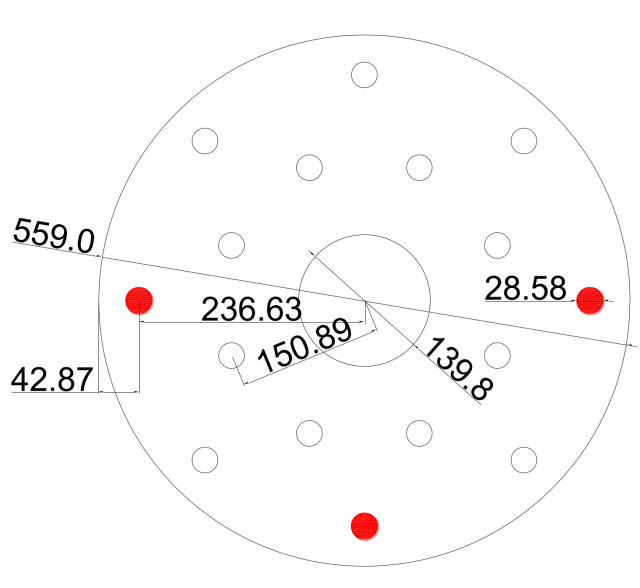

(a)

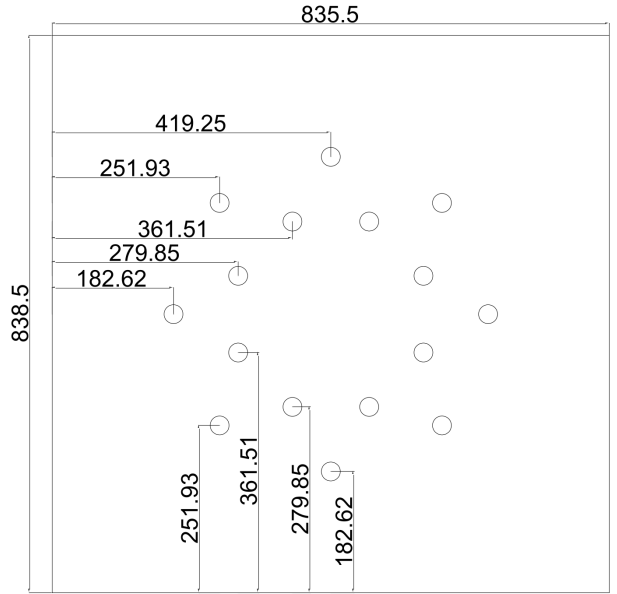

(b)

Figure 4. Location of piles: (a) foundation; (b) bedrock (unit: $\mathrm{mm}$ ). 


\subsection{Procedure of the Experiment}

To verify the effectiveness of the wind turbine foundation reinforced with piles, the method of model experiments was to install bedrock and install an embedded rock layer, as shown in Figure 5a,b. In addition, as shown in Figure 5c,d, wind turbine foundation was installed, and wind turbine towers and foundations were joined together. Figure 5 shows that the wind turbine tower and foundation parts are joined together after the piles are penetrated in experiments of Case 3-6. Finally, after the installation and preparation of the model was complete, a displacement transducer was installed in the horizontal and vertical directions (overturning) of the top and foundation parts of the wind turbine tower, respectively, as shown in Figure 5f. The load point was applied at a point $2800 \mathrm{~mm}$ from the lower part of the tower through the moment equilibrium of the location value of each wind load and the centroid working on blade, nacelle, and tower, with a limited speed of $1 \mathrm{~mm} / \mathrm{min}$ to avoid any effect on load speed. Figure 6 shows the overall experimental devices. The lateral force device was connected to the reaction frame to measure lateral resistance. The rock ground was made of cement mortar, and the laboratory floor was also made of concrete, so an experiment was conducted so that the concrete block of the rock ground did not overturn or slide.

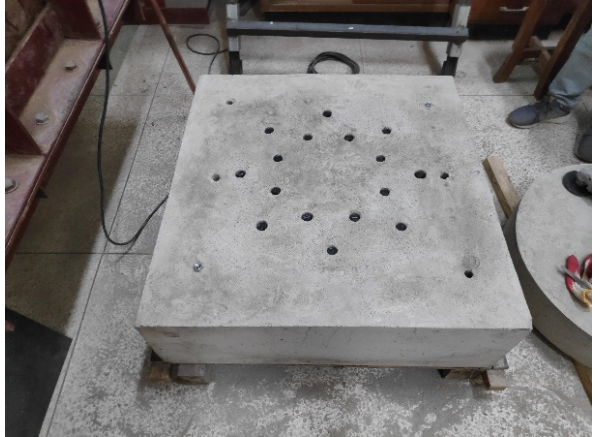

(a)

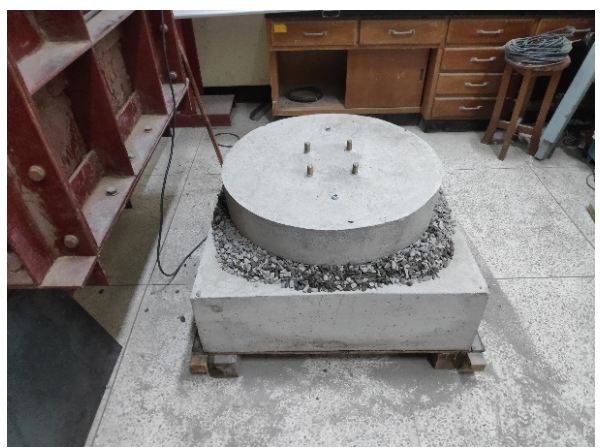

(c)

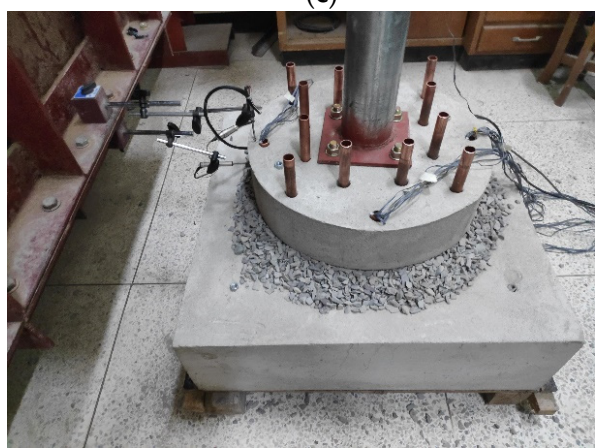

(e)

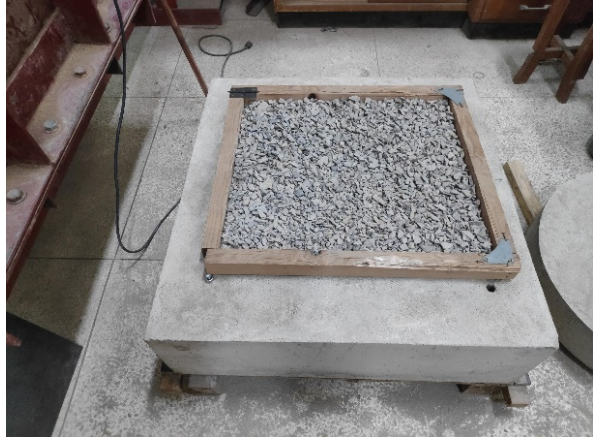

(b)

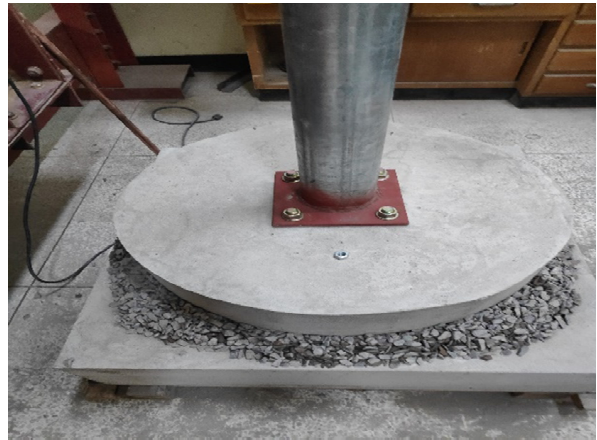

(d)

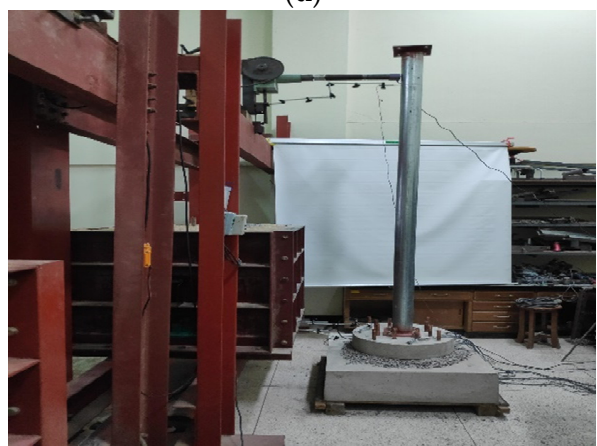

(f)

Figure 5. Procedure for the construction of the model: (a) base ground installation; (b) rubble 
mound layer laying; (c) wind turbine foundation installation (existing type); (d) wind turbine tower connection; (e) pile penetration (reinforced piles); (f) measuring instrument installation and experiment view.

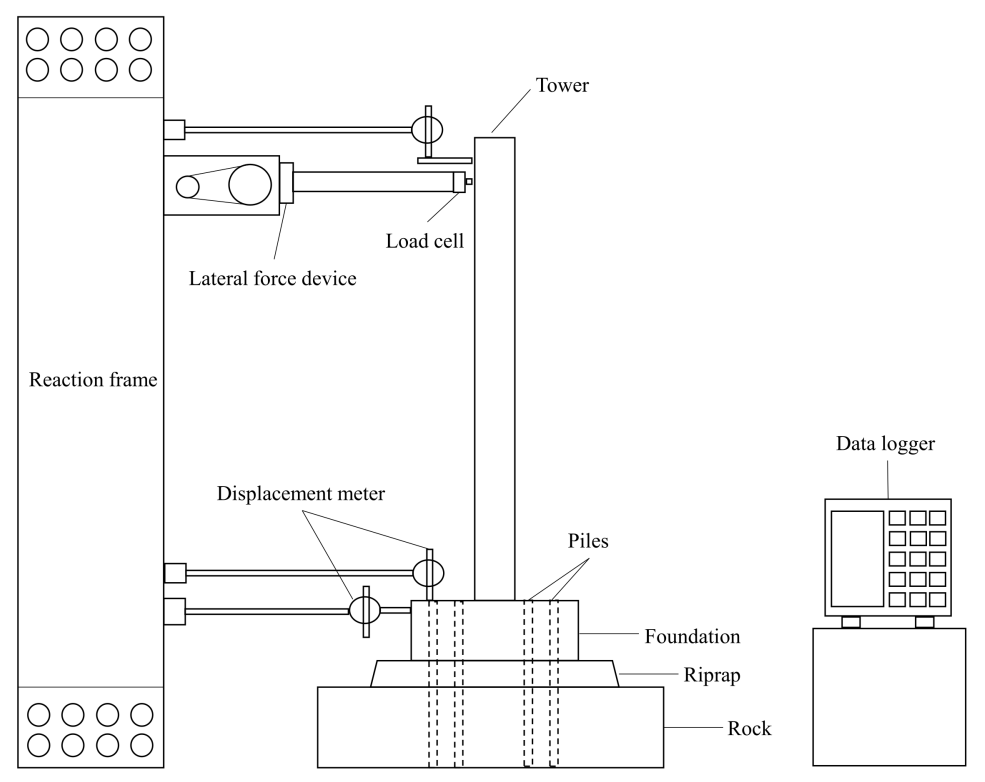

Figure 6. Layout of model experiment apparatus.

\section{Results and Consideration of Modeling Experiment}

\subsection{Lateral Resistance}

Figure 7 is a comparison of the lateral resistance forces according to foundation form. When there are no piles (Case 1,2), horizontal displacement measured up to $25 \mathrm{~mm}$, at which the lateral resistance force converged to a constant value. The lateral resistance measurement showed that Case 1, with large wind foundation size, was $145.04 \mathrm{~N}$, and Case 2 was $98.98 \mathrm{~N}$, which showed that the larger foundation had 1.47 times (46 N) greater resistance.

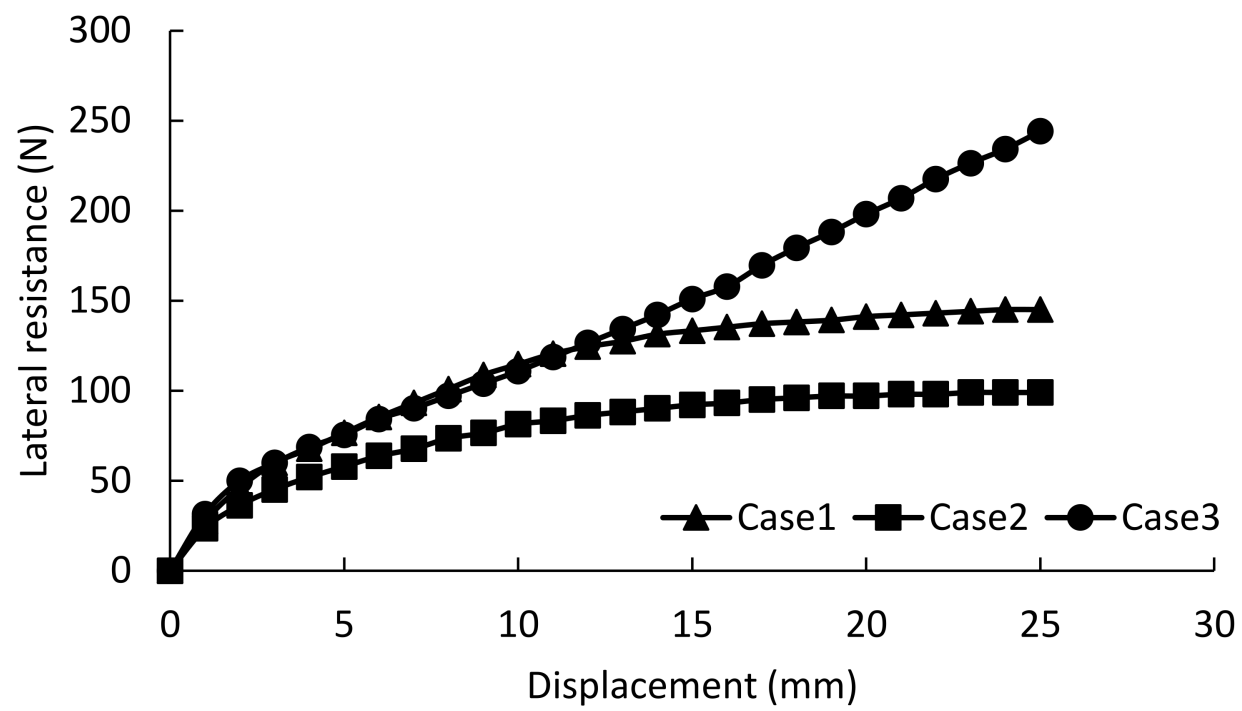

Figure 7. Lateral resistance displacement according to foundation type.

For Case 3 with reinforced piles, it showed a similar tendency to Case 1 up to $11 \mathrm{~mm}$ horizontal displacement, but it also showed a linear increase in resistance without converg- 
ing due to pile effects. At $25 \mathrm{~mm}$ horizontal displacement, the lateral resistance of Case 3 $(244.02 \mathrm{~N})$ was 1.68, which was 2.47 times larger than Case 1 and Case 2, respectively. In other words, when reinforcing piles on the foundations with a reduced cross-section (diameter of $16 \mathrm{~m}$ ), the increasing tendency of existing wind foundations (diameter of $20 \mathrm{~m}$ ) showed a similar tendency to initial lateral resistance, and it showed that lateral resistance was greater when the piles were reinforced after $10 \mathrm{~mm}$ displacement.

\subsection{Comparison of Overturning Effects according to Foundation Type}

To examine trends in the overturning of wind foundations, displacement transducers were installed in the left side of the foundation in both vertical and horizontal directions, respectively, as shown in Figure 8. Through this displacement transducer, the uplift phenomenon of the foundation was quantitatively evaluated, due to overturning of the wind turbine foundation under external force.

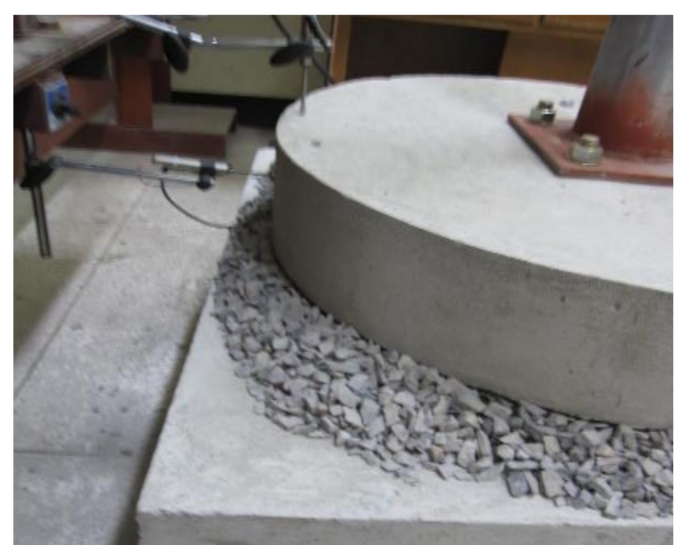

(a)

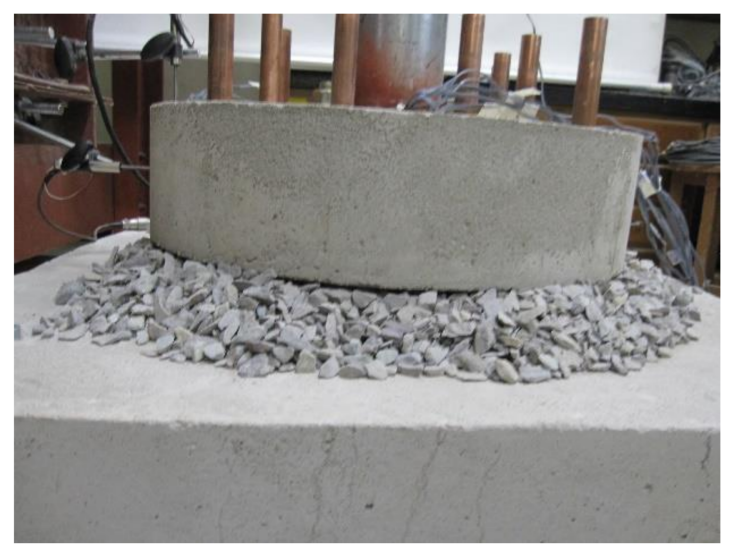

(b)

Figure 8. Overturning of wind turbine foundation: (a) overturning (existing type); (b) overturning of wind turbine foundation reinforced with piles.

Figure 9 is intended to determine the effect of overturning in the pile-reinforced wind turbine foundations by measuring the vertical displacement of wind turbine foundations when lateral loads act on wind towers. For Case 1, the diameter of the foundation is larger than in Cases 2 and 3, which results in larger vertical displacement values measured at the end of the foundation. Therefore, to compare the positions of the same vertical displacement, the position of vertical displacement of Case 1 was corrected to be the same position as Case 2, and the vertical displacement was newly calculated as Case 1-1. The results show that, for wind turbine foundations without piles (Case 1-1 and 2), the vertical displacement for lateral loads is approximately the same. However, in the case of wind foundations reinforced with piles (Case 3), the vertical displacement was 36\% smaller than the case without piles (Case 1-1,2). This showed that wind turbine foundations reinforced with piles have an advantage in overturning over existing wind turbine foundations without piles.

\subsection{Lateral Resistance according to Increasing Weight of Tower}

We then conducted a model experiment in accordance with the Law of Similarity by Iai (1989) [10]; however, in terms of tower weight, it did not satisfy the Law of Similarity. In other words, even though the weight of the model experiment should be $7.44 \mathrm{kN}$ when following the Law of Similarity, it was impossible to produce a model tower capable of satisfying the weight of $7.44 \mathrm{kN}$. Therefore, to evaluate the effect on the weight of the tower, as shown in Figure 10, the experiment was conducted to enable the estimation of the lateral resistance force to the weight of the tower by applying an additional overburden load on the top of the tower. 


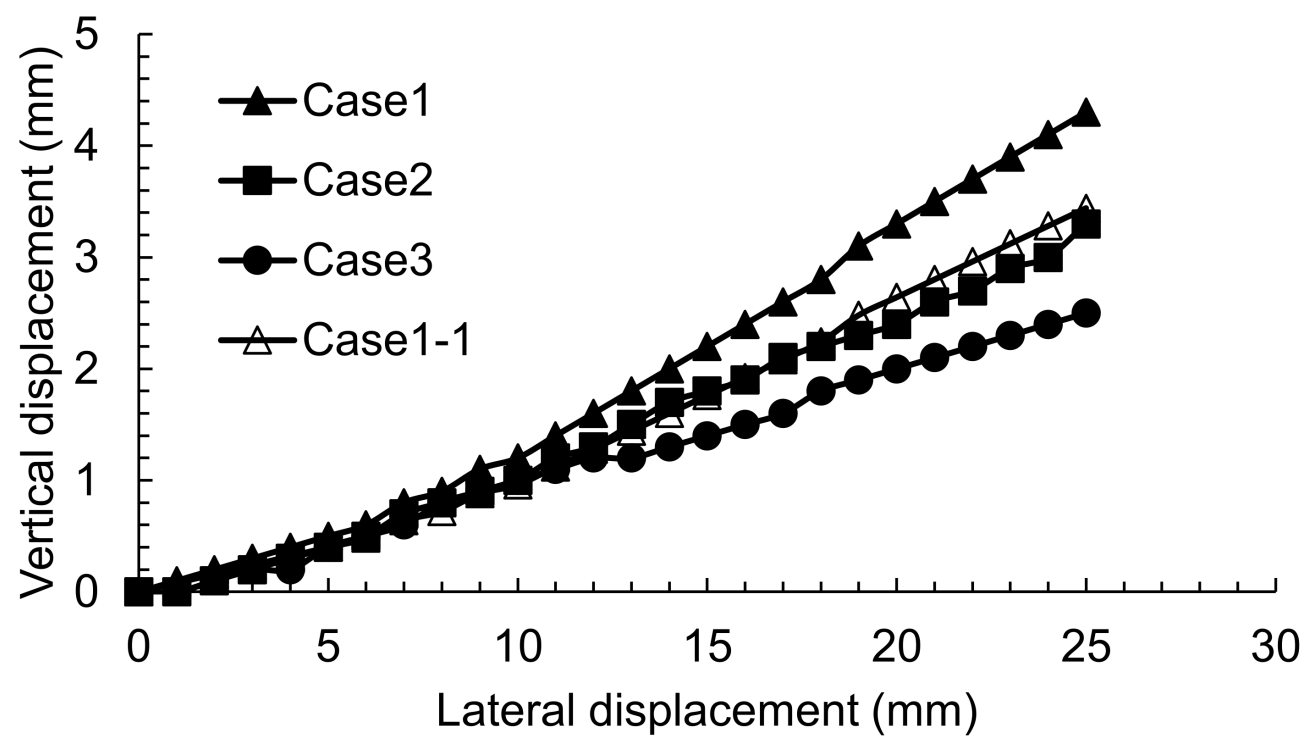

Figure 9. Vertical displacement according to foundation type.

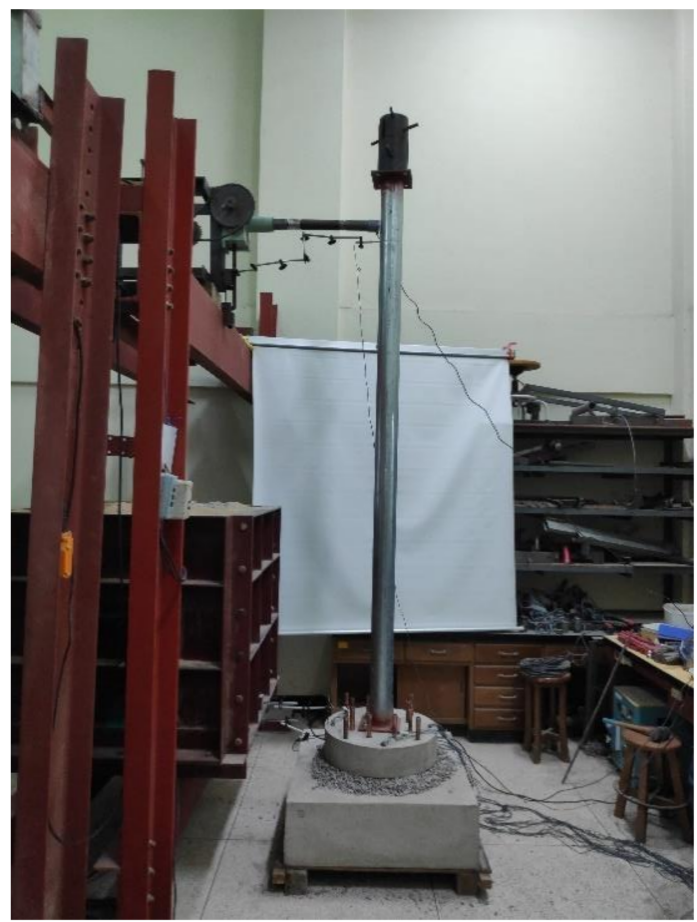

Figure 10. Increased self-weight experiment for tower.

Figure 11 represents the lateral resistance of Case 3 (357.7 $\mathrm{N}$ of tower weight), a pile-reinforced tower foundation, and Cases 4 and 5 with double and triple the tower weight of Case 3. At the point where the displacement of the head of the tower occurred at $25 \mathrm{~mm}$, the lateral resistance forces of Cases 3, 4, and 5 were $244.02 \mathrm{~N}, 257.74 \mathrm{~N}$, and $272.44 \mathrm{~N}$, respectively. In other words, the lateral resistance tended to increase as the tower's self-weight increased. 


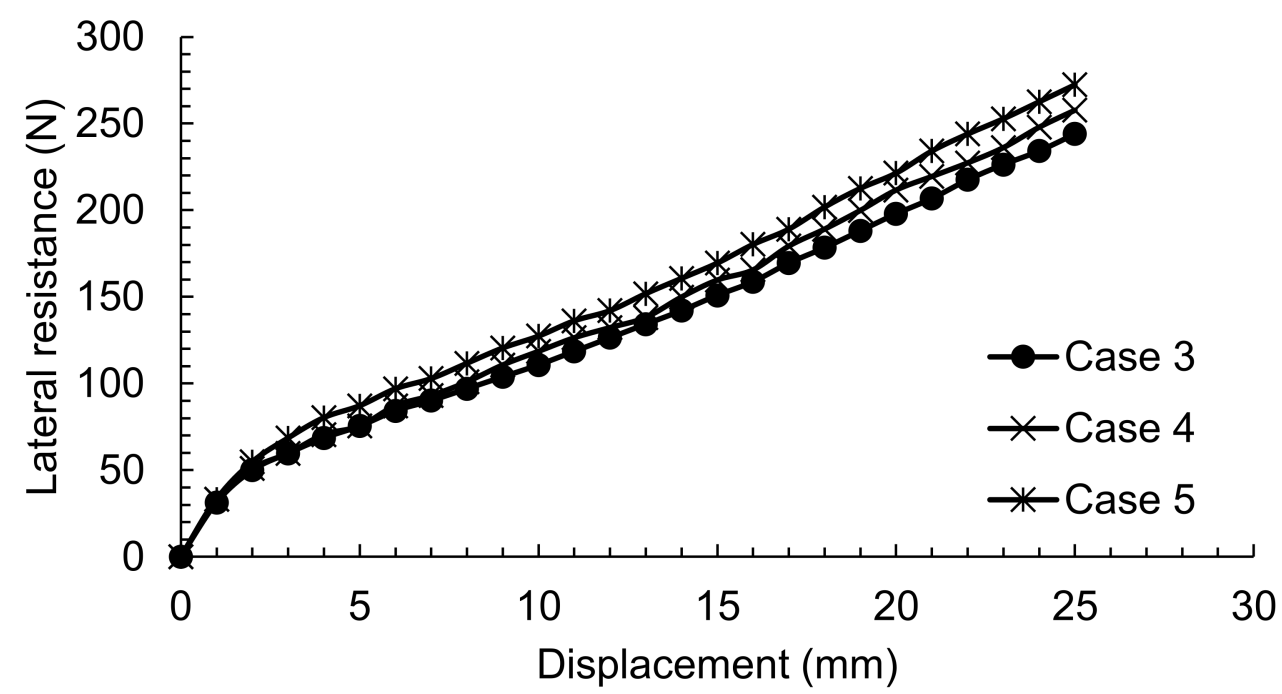

Figure 11. Lateral resistance according to the change in overhead load.

Figure 12 represents the lateral resistance ratio according to the tower weight ratio. Figure 12 provides an expression for estimating the value of lateral resistance due to increased self-weight, as shown in Equation (1). Therefore, if the tower weighs $7.44 \mathrm{kN}$ in accordance with the Law of Similarity, it can be predicted that the lateral resistance force can be $524.99 \mathrm{~N}$.

$$
P=0.058 n+0.941
$$

$P$ : Lateral resistance ratio of the tower;

$n$ : Load increase ratio.

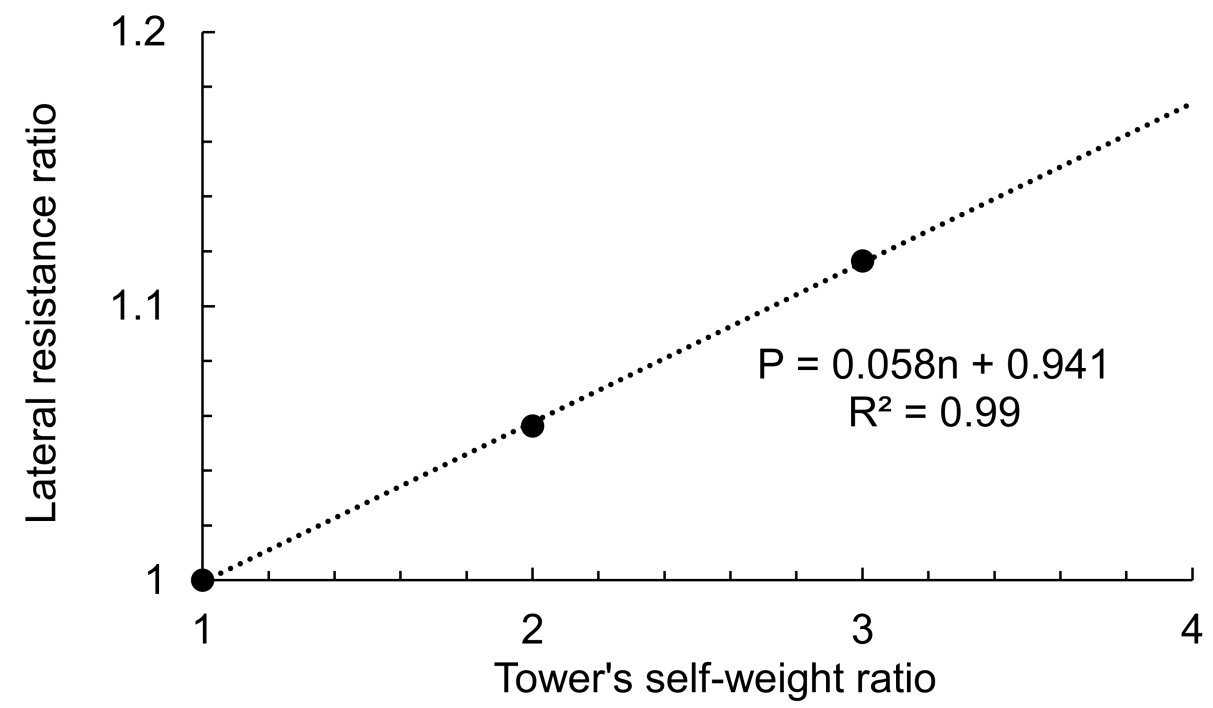

Figure 12. Lateral resistance ratio according to tower weight ratio.

\subsection{Lateral Resistance According to Cyclic Loading}

As structures are affected by wind loads, offshore tower foundations require behavior evaluations of a cyclic loading. To this end, the target displacement was applied at intervals of $5 \mathrm{~mm}$, and the maximum displacement was subjected to a total of 5 cyclic loadings up to $25 \mathrm{~mm}$ (Case 6). The cyclic loading was measured repeatedly by applying the load up to a certain target displacement and it was unloaded until 0 (zero) value using the lateral force device shown in Figure 6. 
Figure 13 represents the lateral resistance of the tower foundation according to cyclic loading, and the elastic recovery displacement and recovery displacement amounts according to cyclic loading are shown in Table 5, with a larger recovery ratio for a larger target displacement. In addition, the maximum lateral resistance value according to the target displacement value was similar when compared to Case 3, which operated static loads. These results are believed to be due to the large amount of elastic recovery due to the wind turbine foundation and piles embedded on bedrock.

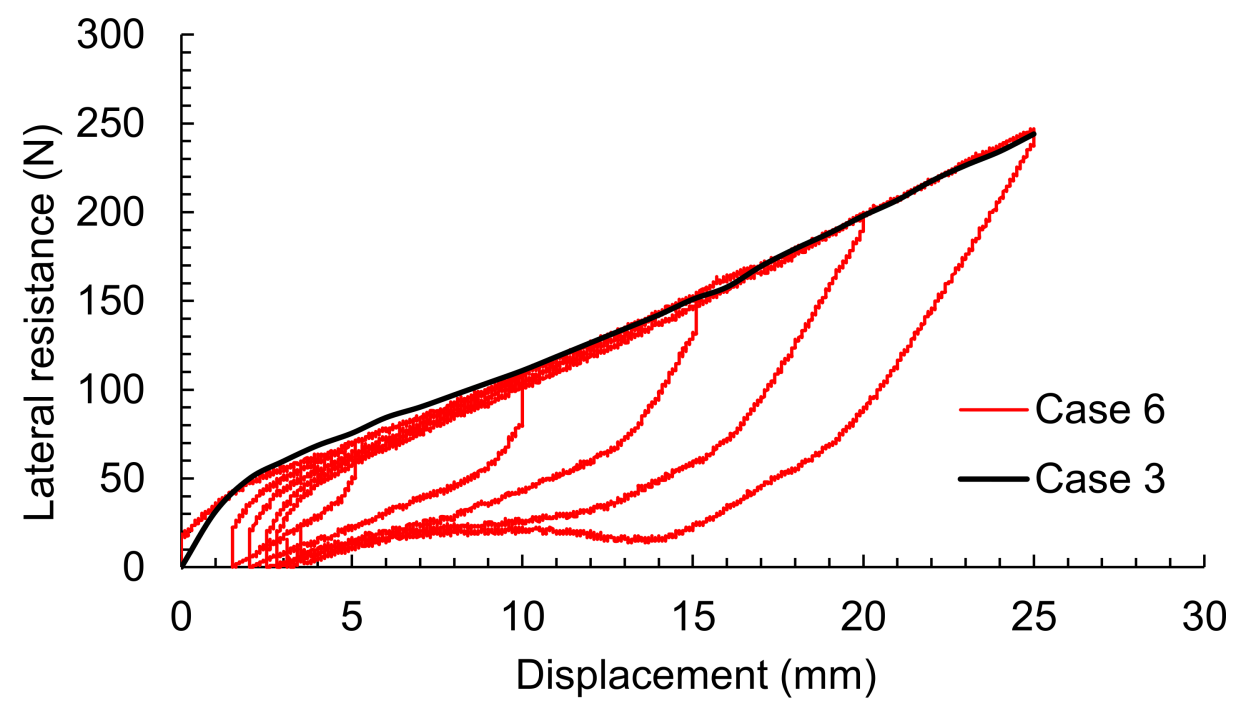

Figure 13. Lateral resistance according to cyclic loading.

Table 5. Elastic recovery ratio according to target displacement.

\begin{tabular}{lccccc}
\hline Target displacement $(\mathbf{m m})$ & 5 & 10 & 15 & 20 & 25 \\
Recovery displacement $(\mathbf{m m})$ & 3.5 & 8 & 12.4 & 17.2 & 21.9 \\
Elastic recovery ratio $(\%)$ & 70 & 80 & 82.67 & 86 & 87.6 \\
\hline
\end{tabular}

\subsection{Bending Moment of a Pile}

In order to observe the behavior of a pile, the bending moment of the pile can be calculated using the value of the strain gauge installed on the pile, and it can be expressed as shown in Equation 2 for calculating the bending moment (Rollins et al., 1998) [11].

$$
\mathrm{M}=\frac{E I \cdot I \cdot \epsilon}{d}
$$

$\epsilon$ : Strain rate;

EI: Bending rigidity of model pile;

$d$ : Radius of model pile.

Figure 14 represents the bending moment by pile position (Figure 4). The bending moment of the pile was measured in three locations, and was expressed as: Figure 14a front row, located in a straight line ahead of the direction of loading; Figure 14b back row, located at the very rear; and Figure $14 \mathrm{c}$ right-hand row, located outside the front row $\left(90^{\circ}\right.$ counterclockwise point). The y-axis of Figure 14 was expressed as dimensionless by the ratio between the height of the tower foundation and the embedded depth. For overturning, the maximum bending moment point of action was shown at approximately the -1.0 point, the boundary surface between the floor of the tower foundation and the rubble mound layer. In addition, it was shown at approximately the -1.5 point in the cases of the back row and right-hand row, indicating the boundary surface between the floor of the rubble mound layer and bedrock. The maximum bending moment was $2398 \mathrm{~N} \cdot \mathrm{cm}$ in the front row, $1014 \mathrm{~N} \cdot \mathrm{cm}$ in the right-hand row, and $914 \mathrm{~N} \cdot \mathrm{cm}$ in the back row. It has the 
same form as in the pile foundation with general lateral load, where the front row has the greatest resistance, followed by the right-hand row and the back row.

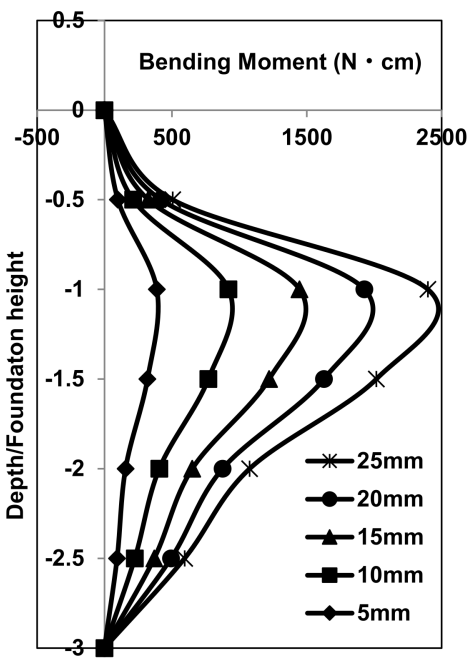

(a)

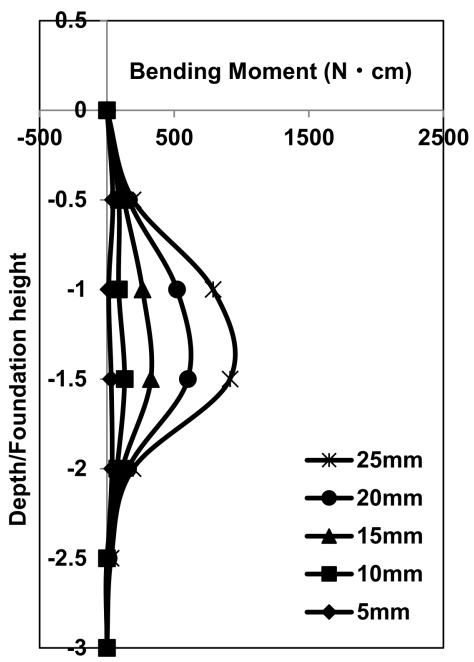

(b)

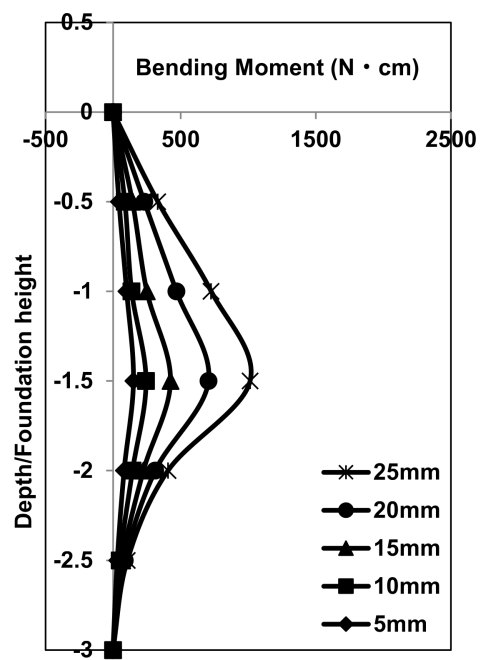

(c)

Figure 14. Bending moment by pile position: (a) front row; (b) back row; (c) right-hand row.

\section{Conclusions}

This study conducted model experiments to examine the lateral resistance of the wind turbine foundations reinforced with piles on bedrock and the member force of piles. The results are as follows:

(1) Comparing the lateral resistance of existing wind turbine foundations with large cross-sections (Case 1) and a wind turbine foundation reinforced with piles (Case 3), our study showed a similar tendency to change the lateral resistance force up to the initial $10 \mathrm{~mm}$ of displacement. However, over $10 \mathrm{~mm}$, Case 1 had a slight increase in lateral resistance, and Case 3 tended to increase linearly at a rapid pace. At a displacement of $25 \mathrm{~mm}$, Case 3, reinforced with piles, had an effect 1.68 times greater than Case 1.

(2) The vertical displacement at the foundation part measured to verify the effectiveness of existing wind turbine foundations with a large cross-section (Case 1), as well as wind turbine foundations reinforced with piles on overturning, was 36\% smaller in Case 3 compared to Case 1 . This shows that the pile-reinforced wind turbine foundations have better safety for overturning.

(3) As a result of operating cyclic loading on the pile-reinforced wind turbine foundations (Case 6), lateral resistance at the target displacement value was similar compared to Case 3, which was subjected to static loading. In addition, the elastic recovery ratio was up to $87.6 \%$, which can be seen as a result of a large elastic recovery due to piles embedded in the bedrock.

(4) As a result of examining the member force of piles through bending moment, the front row close to the loading point showed a greater bending moment than the right-hand and back rows; the maximum bending moment occured between the base of foundation and the rubble mound layer.

(5) The above results confirmed that wind turbine foundations reinforced with piles have superior lateral resistance and stability in relation to overturning compared to existing gravity-based wind turbine foundations with large cross-sections.

Author Contributions: Conceptualization, methodology, J.K. and G.K.; modeling tests and data curation, S.-K.Y. and T.-H.K.; writing-original draft preparation, G.K. and J.K.; writing-review and editing, J.K. and G.K.; supervision, G.K.; funding acquisition, G.K. All authors have read and agreed to the published version of the manuscript. 
Funding: This research was supported by the Basic Science Research Program through the National Research Foundation of Korea (NRF) funded by the Ministry of Education (No. 2020R1I1A3067248)

Institutional Review Board Statement: Not applicable.

Informed Consent Statement: Not applicable.

Data Availability Statement: All data generated or analyzed during this study are included in this manuscript.

Acknowledgments: The authors acknowledge Dongju Kim and Manwoong Ha for their support and thank them for conducting modeling experiments with them.

Conflicts of Interest: The authors declare no conflict of interest.

\section{References}

1. Kim, T.H.; Kim, J.; Choi, J.S.; Kang, G. Evaluation of Lateral Resistance for Tie-cell Wave-dissipating Block by Model Experiments. J. Korean Geotech. Soc. 2020, 36, 87-97.

2. Gregory, P.; Tsinker, G. Handbook of Port and Harbor Engineering; Springer US: New York, NY, USA, 1997.

3. Kang, G.; Kim, J.; Kim, T.-H.; Lee, S.; Kim, J. Lateral Resistance of Block Type Breakwater with Piles to Depth of Embedment. J. Korea Soc. Coast. Ocean. Eng. 2021, 32, 65-72. [CrossRef]

4. Negro, V.; López-Gutiérrez, J.S.; Esteban, M.D.; Matutano, C. Uncertainties in the Design of Support Structures and Foundations for Offshore Wind Turbines. Renew. Energy 2014, 63, 125-132. [CrossRef]

5. Esteban, M.D.; López-Gutiérrez, J.S.; Negro, V.; Matutano, C.; García-Flores, F.M.; Millán, M.A. Offshore Wind Foundation Design: Some Key Issues. J. Energy Resour. Technol. ASME 2015, 137, 051211. [CrossRef]

6. Houlsby, G.T.; Ibsen, L.B.; Byrne, B.W. Suction Caissons for wind turbines. In Proceedings of the 1st International Symposium on Frontiers in Offshore Geotechnics (ISFOG), Perth, Australia, 19-21 September 2005; pp. 75-94.

7. Kelly, R.B.; Houlsby, G.T.; Byrne, B.W. A comparison of field and laboratory caisson tests in sand and clay. Geotechnique 2006, 56, 617-626. [CrossRef]

8. Esteban, M.D.; López-Gutiérrez, J.S.; Negro, V. Gravity-Based Foundations in the Offshore Wind Sector. J. Mar. Sci. Eng. 2019, 7,64. [CrossRef]

9. Li, Y.; Cheng Ong, M.; Tang, T. Numerical Analysis of Wave-induced Poro-elastic Seabed Reponse Around a Hexagonal Gravity-based Offshore Foundation. Coast. Eng. 2018, 136, 81-95. [CrossRef]

10. Iai, S. Similitude for Shaking Table Tests on Soil-Structure-Fluid Model in 1g Gravitational Field. Soil Found. 1989, 29, 105-118. [CrossRef]

11. Rollins, K.M.; Peterson, K.T.; Weaver, T.J. Lateral Load Behavior of Full-Scale Pile Group in Clay. J. Geotech. Geoenvironmental Eng. ASCE 1998, 124, 468-478. [CrossRef] 